\title{
LOS TRES PRIMEROS ACTOS DEL YO: LA INTUICIÓN INTELECTUAL, EL CONCEPTO DEL YO Y LA DUALIDAD FACULTAD / NO-YO (\$\$ 1 Y 2)
}

\author{
THE FIRST THREE ACTS OF THE I: \\ INTELLECTUAL INTUITION, THE CONCEPT OF I \\ AND THE DUALITY FACULTY/NON-I (\$§ 1 AND 2)
}

\author{
JACINTO Rivera DE Rosales
}

UNED

Comenzamos aquí la narración de la génesis del Yo y de su mundo de la experiencia, la que nos muestra la DC (Doctrina de la Ciencia) en esta su segunda versión pública. (1) Veremos antes algunas cuestiones metodológicas a fin de aclarar de qué estamos hablando, mostrando de ese modo el marco de referencia. (2) Pasaremos después a la cuestión del primer principio, tan debatida en aquel entonces. (3) En tercer lugar determinaremos cuál es el primer principio para Fichte y cómo éste es una acción, y en concreto una intuición intelectual. (4) A continuación estudiaremos el segundo momento o acción del Yo en su génesis, a saber, el concepto del Yo, que da lugar a la contraposición actividadreposo. (5) El quinto y último punto consistirá en el análisis del tercer momento o acción del Yo, en la que aparecerá el reposo como lo indeterminado determinable, y en concreto en una inevitable dualidad: primero como facultad (Vermögen) o potencia del Yo, y en segundo lugar como el No-Yo ${ }^{1}$.

\footnotetext{
${ }^{1}$ Este artículo ha salido beneficiado del seminario privado que tuve con Óscar Cubo, Ana Carrasco y Vasco de Jesús, en donde tuvimos ocasión de discutir largamente sobre estos textos. A ellos mi agradecimiento en especial, así como a los miembros de la RIEF que han tenido a bien participar en este complejo proyecto.
} 


\section{Cuestiones metodológicas}

En el $§ 1$ comienza la exposición de la DC propiamente dicha. En ella se expone la génesis del Yo en sus diversos momentos, es decir, en la serie de sus diversas acciones, gracias a las cuales el Yo se construye o se configura como Yo, surgiéndole en el camino los diversos aspectos de su mundo. No se trata de deducir los elementos empíricos de la experiencia; la WL no pretende deducir todas las clases de animales, los diversos planetas o las razas humanas, sino que lo que aquí se expone son los momentos transcendentales a priori, aquellos que configuran y estructuran toda la experiencia o saber de cualquier ser racional finito, con ese carácter de universalidad y necesidad que Kant señalaba como características de lo a priori ${ }^{2}$.

Esto nos indica que el Yo del que hablamos no es meramente el individuo, aunque el término "yo" se use comúnmente en ese sentido. Aquí se utiliza para designar la esencial autorreferencia a sí (o el para-sí) que caracteriza al Yo como realidad-idealidad y que hace posible la autoconciencia y con ello también la conciencia de lo otro de sí. Fichte no deduce el mundo, toda nuestra experiencia, a partir del individuo, más bien al contrario, pues esas acciones transcendentales dan lugar tanto al individuo como a la comunidad así como a la experiencia objetiva del mundo, y nos explica cómo todo eso es para el Yo, cómo el Yo sabe de la realidad. El Yo que se autopone y autofunda no es el del individuo que dice "yo», pues éste aparecerá como un resultado posteriormente, en los últimos parágrafos de la WLnm (Wissenschaftslehre nova methodo = Doctrina de la Ciencia nova methodo) ${ }^{3}$. El Yo transcendental en realidad da lugar a los seis pronombres personales tomados empíricamente; es a la vez tanto un yo como un tú, un él/ella, un nosotros, un vosotros y un ellos. Es la condición de posibilidad de todas esas articulaciones de la subjetividad, y ninguna de ellas sería posible sin las otras. "Mi Yo absoluto no es, evidentemente, el individuum, le dice Fichte a Jacobi en carta del 30-8-1795 [...]. Pero el individuo ha de ser deducido del Yo absoluto. Para eso la DC ha de ocuparse sin tardanza del derecho natural [...] Las condiciones de la indivi-

\footnotetext{
${ }^{2}$ Kant, $K r V$, Introducción II, B 3-6.

3 También por eso el Yo transcendental se suele escribir en español con mayúscula, mientras que el yo del individuo, el empírico ( $1^{a}$ persona), lo tendríamos que poner con minúscula.
} 
dualidad se llaman derechos» ${ }^{4}$. No obstante la WLnm toma pronto la vía del yo individual, pero para remontarse desde el final del $\S 13$ a la comunidad de seres racionales como condición de posibilidad de todo individuo y de toda conciencia, o sea, va de la acción individual del Yo (lo determinado) hasta el marco o conjunto (lo determinable) desde el cual esa acción se comprende y es posible. «El hombre (así como todo ser finito en general) sólo entre hombres se hace hombre» ${ }^{5}$.

Esos momentos a priori, deducidos en el sistema, son acciones del Yo. Aquí todo será explicado mediante acciones. Incluso la limitación, que es igualmente originaria, la ha de elaborar el Yo desde sí para que él se entere de ella y sea para él; mostrar cómo eso es posible desde la acción del Yo constituye propiamente la explicación y deducción idealista y genética que aquí se procura, pues únicamente entonces se ve que esa determinación no sólo es, sino que también es un saber y que por tanto podemos hablar de ella con fundamento. La acción es lo primero ${ }^{6}$, pues es lo que explica el objeto, lo fijo, lo substante, y no a la inversa; la acción puede pararse, determinarse a hacer esto y no aquello, encontrar obstáculos o autolimitarse por respeto al otro, mientras que lo inerte nunca podrá tener acción propia ni protagonizada ni conciencia de sí ni provocarla o comunicarla a otro. El Yo no es una substancia, algo que meramente fuera y después actuara, una res que tuviera como atributo el pensar, sino que su ser es primariamente acción, agilidad, a partir de la cual, y para comprenderse por medio de la contraposición, construye lo que aparece como parado, substrato, substante, incluso de sí mismo. La realidad es primariamente acción, y sobre ella se monta todo lo demás.

${ }^{4}$ GA III/2, 392. Véase también ZE $\$$ 9, 11 y 12, donde leemos: "En la Doctrina de la Ciencia, la relación es justamente la contraria ; allí es la razón lo único en sí y la individualidad sólo accidental; la razón, fin, y la personalidad, medio; esta última únicamente una manera particular de expresar la razón, manera particular que se ha de ir perdiendo cada vez más en la forma universal de la razón. Sólo la razón es eterna para la Doctrina de la Ciencia; la individualidad por el contrario ha de extinguirse continuamente" (ZE, GA I/4, 257-258).

${ }^{5}$ GNR, $\$ 3$ (Corolarios), GA I/3, 347. "Tampoco puede Kant entender con esa apercepción pura la conciencia de nuestra individualidad, ni mezclar esta última con la primera; pues la conciencia de la individualidad va necesariamente acompañada por otra conciencia, la de un Tú, y sólo es posible bajo esa condición" (ZE, GA I/4, 229).

6 "Am Anfang war die Tat, o sea, "al principio fue la acción", hace decir Goethe a su Fausto (v. 1237). 
Por medio de esas acciones lo que el Yo busca es saber de sí, y por tanto ser y realizarse como Yo, como razón teórico-práctica, pues el Yo es en la medida en que sabe de sí, en él ser y saber se identifican, y gracias a esa identificación surge el $\mathrm{Yo}^{7}$. Pero esa identidad que se da al principio no es pétrea y cerrada, sino que está necesariamente abierta a lo otro de sí y se encuentra con límites y fracturas, en definitiva porque el camino hacia el saber de sí pasa por contraponerse a lo otro de múltiples maneras como ley necesaria del pensar y del conocer, y porque su misma identidad es acción transformadora. Por eso el Yo es una tarea, en el fondo una tarea moral para realizar su ser, su libertad racional, cuyo ser se le presenta como deber ser. Esto es lo que empuja y dinamiza todo el sistema, aquello que lo convierte en acciones múltiples y determinadas, conectadas entre sí sintéticamente. Todos los momentos o acciones son deducidos como condiciones de posibilidad de la autoconciencia o Yo, y lo que se ve a lo largo del sistema es la génesis del Yo y de su mundo.

Que la exposición filosófica de ese surgimiento del Yo y su mundo sea genética significa que esas acciones se montan o se enhebran las unas sobre las otras, como en una historia del surgimiento de la conciencia ${ }^{8}$, en el sentido de que la posterior es una reflexión sobre la acción anterior, una nueva reflexión que necesita llevar a cabo el Yo para enterarse de esa acción anterior. Pero sucede que el Yo no logra ver que todos esos momentos son acciones suyas, al menos idealiter, no capta su propia acción en el pensar (en el poner) las condiciones de posibilidad de sí mismo, o su acción de trasferirle al mundo un ser en sí, etc. De ese modo le surge el sentimiento de realidad como algo enteramente independiente de su acción con el que se le presenta el mundo y su propia existencia, y mediante ese no-ver-se u olvido de sí nace la conciencia natural y su punto de vista meramente realista. Se precisa justamente una reflexión transcendental, filosófica, para poder recuperar lo perdido en una especie de anámnesis, a fin de que el Yo se comprenda plenamente, no se aliene, no quede dividido, cosificado, no-libre: hay que arrancarle las cadenas de la cosa en sí y hacerle ver que el objeto no es lo primario, como piensa el dogmático (según la terminología fichteana). «La metafísica no ha de ser en modo alguno una doctrina de las pretendidas cosas en sí, sino una deducción genética de lo

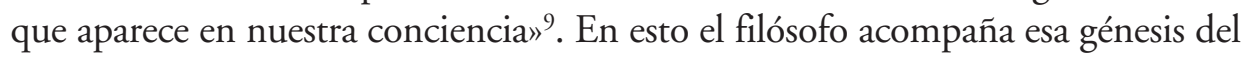

7 WLnm-K, GA IV/3, 481.

${ }^{8}$ WLnm-K, GA IV/3, 464

${ }^{9}$ BWL $2^{\underline{a}}$ ed., GA I/2, 159. Ha de ser una metafísica de la libertad, había escrito Kant en sus Progresos de la metafísica desde Leibniz y Wolff, que no llegó a publicar. 
Yo, no produce sus acciones sino que las observa, las anota, relata su historia, cómo actúa según sus leyes y le surge un mundo, cómo se producen los puntos de vista del Yo distintos de la visión del filósofo, al igual que el autor de un drama abarca y supera la visión de cada uno de sus personajes, pues sabe desde el inicio toda la obra, lo que va a suceder y el final:

«La Doctrina de la Ciencia no es, para decirlo de algún modo, ella misma generatriz de un conocimiento, sino que es meramente observación del espíritu humano en el generar originario de todo conocimiento, pero el sistema kantiano no va hasta el final en la observación como lo hace la Doctrina de la Ciencia. El sentido común actúa, por cierto, y observa solamente el producto de su actuar. [...] La Doctrina de la Ciencia pone atención en el actuar mismo [...]. Sólo así surge su intelección genética del origen de nuestras representaciones» ${ }^{10}$.

La exposición filosófica, además de genética, es sintética, es decir, tiene en cuenta tanto la unidad del Yo transcendental a lo largo de todas esas acciones suyas gracias a las cuales surge como la diferencia (análisis) o pluralidad de las mismas. "En la conciencia todo es a la vez unido y separado» ${ }^{11}$. Ambos momentos son esenciales: sin distinción y sin unidad a la vez no habría conciencia ni autoconciencia, o sea, no existiría un Yo. Sin distinción habría confusión total respecto a todos los elementos que constituyen nuestra experiencia, confusión entre sujeto y objeto, entre los diferentes sujetos y los distintos objetos, etc.; la unidad del Yo es una unidad en la diferencia. Pero sin unidad el Yo se perdería en mundos totalmente separados que no sabrían el uno del otro, de manera que la identidad del Yo quedaría quebrada, rota; la diferencia se establece en una unidad que las liga, las compara, las comprende como tales, como relacionadas entre sí. Por tanto el relato genético de los diferentes momentos del Yo ha de ser «por medio de un progreso sintético»" ${ }^{12}$.

10 WLnm-K, GA IV/3, 480.

11 WLnm-K, GA IV/3, 359. "En la unificación es separado, y en la separación unificado, ambas cosas son inseparables" (o. c., 475). "El comienzo de toda conciencia es síntesis y análisis a la vez, y por medio de esta última surge una multiplicidad" (o. c., 476).

12 WLnm-K, GA IV/3, 344. 
Por último es importante tener en cuenta la diferencia que hay entre la forma sucesiva y temporal del relato que la filosofía hace de esa génesis del Yo y de su mundo, o sea, de sus sucesivas acciones por un lado, y la simultaneidad real de todo lo relatado por otro lado, pues ninguna de esas acciones es posible sin las otras, y por tanto la prioridad de una sobre la siguiente no es temporal sino transcendental y ontológica. Si bien la exposición filosófica de esas acciones del Yo transcendental las hace desfilar unas después de las otras, en una serie sucesiva a lo largo de los diferentes parágrafos, en realidad ellas ocurren de un golpe (im einem Schlage), todas a la vez. Eso es así, primero, porque no hay lapso de tiempo, no hay temporalidad entre ellas, puesto que son acciones transcendentales y no empíricas, y, segundo, porque todas ellas son propuestas como condiciones de posibilidad de la autoconciencia, de manera que si una faltara, faltarían todas. Y sin embargo la presentación sucesiva de las acciones tiene también su razón de ser, no es arbitraria, sino que va desde el fundamento hasta lo fundado, es decir, desde las acciones más originarias que abre todo el espacio del ser-saber y hacen posible las demás, hasta las acciones que van estableciendo sucesivas mediaciones y puentes en la contraposición básica en la que se ve envuelto el primer acto. Las primeras acciones son la base de las siguientes, pero éstas últimas son asimismo condiciones de posibilidad de las primeras, sin las cuales aquéllas se hundirían en una contradicción irresuelta e irresoluble que las haría imposible, y por eso son también deducidas con un razonamiento que podríamos esquematizar así: si se da la conciencia, entonces es necesario esto y esto y esto, es así que se da la conciencia, entonces se da asimismo esto y esto y esto. O usando otro tipo de metáforas, podríamos decir que en la exposición filosófica se va desde el centro del Yo (su intuición intelectual) a la periferia ${ }^{13}$, al mundo natural como un todo y a la comunidad de seres racionales, pero sin esa periferia el centro no sería posible, y por tanto en realidad se camina en las dos direcciones, con un fundamen-

13 «El dogmático se dirige hacia adentro [al partir su explicación de la conciencia desde la afección de la cosa en síl, el idealista transcendental describe sus radios hacia la periferia; todo viene de dentro, todo presupuesto del exterior no sirve para nada [...] Se trata de explicar todo a partir del centro, hemos de mostrar que no se precisa la perspectiva del dogmático" (WLnm-K, GA IV/3, 463). "Un PERIODUm sintético es siempre quíntuple. Aquí [en la deducción emprendida en la WLnm] tenemos la ventaja de ir desde los [miembros] internos hacia fuera, no como en la Doctrina de la Ciencia impresa [la $G W L$ de fuera hacia adentro. Dentro de esta síntesis se halla todo pensar, pues todo es una determinada autoconciencia” (o. c., 477). 
to que es a la vez posibilitado y condicionado por lo fundado ${ }^{14}$, si bien el centro guarda una cierta preeminencia ontológica y de orientación en el pensar y en la acción.

\section{El primer principio}

Nuestro texto comienza $(\S 1)$ registrando la discusión en torno al primer principio $^{15}$, una discusión que se estaba dando en la época. Fichte se alinea a favor de la necesidad de un primer principio, pues si queremos que la filosofía se configure como un saber fundado y sistemático, y que no se quede en meras opiniones sin orden ni concierto, entonces ese saber ha de ser demostrado, y toda demostración ha de apoyarse a la postre en algo indemostrable si es que no queremos ir hasta el infinito en la cadena de demostraciones y no llegar nunca a un saber finalmente fundado. Por consiguiente ha de haber algo, alguna verdad, algún ser-saber autofundado y autofundante que sirva de base a toda otra afirmación, a cualquier otro saber. ¿Cuál podría ser?

Karl Leonhard Reinhold (Viena 1758 - Kiel 1823) fue el primero en lanzar esa idea dentro del ámbito de la filosofía crítica, la de que a la filosofía kantiana le faltaba un fundamento capaz de conferirle una forma sistemática: «Hasta ahora a todas las filosofías, sin excluir ni siquiera la kantiana cuando se la considera como ciencia, les falta nada menos que un fundamento» ${ }^{16}$.

${ }^{14} \mathrm{El}$ idealismo "muestra que lo primero que ha sido establecido como principio e inmediatamente comprobado en la conciencia no es posible sin que a la par algo distinto suceda; y que este otro tampoco, sin que a la par algo tercero suceda; y así hasta que las condiciones de lo que fue mostrado primero hayan sido agotadas completamente y esto mismo sea, según su posibilidad, concebible en su totalidad. Su andar es un progresar ininterrumpido desde lo condicionado a la condición, en el cual cada condición deviene a su vez un condicionado, cuya condición hay que buscar" (EE $§ 7$; GA I/4, 205)

${ }^{15}$ Este tema lo he tratado más ampliamente en el artículo "El primer principio en Fichte", publicado en el libro El inicio del Idealismo alemán (Editorial Complutense / UNED, Madrid, 1996, pp. 63-102).

${ }^{16}$ Ueber das Fundament des philosophischen Wissens (Meiner, Hamburg, 1978, p. 3). Reinhold publicó ese libro en 1791, que el joven Fichte tuvo en alta estima. "Su excelente escrito sobre el fundamento del saber filosófico lo he leído varias veces, y lo he considerado siempre como la pieza maestra entre sus piezas maestras", le decía Fichte a Reinhold en carta del 1 de marzo de 1794 (GA III/2, 75 y 78) no sin cierta adulación. 
Fichte aceptó esta propuesta de Reinhold. Inicialmente pensó: «Kant posee en general la filosofía correcta, pero sólo en sus resultados, no según sus fundamentos» ${ }^{17}$. Después, en el tiempo de la WLnm, matizó esa posición: a Kant no le faltan los fundamentos, pero sí una ordenación sistemática de los materiales, una deducción genética y completa de los diversos elementos, es decir, sus fundamentos no funcionan como tales, y por eso escribe Críticas y no un sistema. Por ejemplo, en el $\$ 6$ de la Segunda Introducción, donde trata de conectar su filosofía con la kantiana, afirma: «Para mí, a la Critica de la razón pura no le falta un fundamento; se halla ahí de manera bien clara, sólo que no se ha construido sobre él, y los materiales de construcción -aunque están preparados con esmerose encuentran unos junto a otros y superpuestos en un orden muy arbitrario» ${ }^{18}$.

Lo que Fichte no acepta es la formulación que Reinhold hace del primer principio, y que éste denomina "principio de conciencia", habiéndolo formulado de la siguiente manera: «En la conciencia, la representación es diferenciada del sujeto y del objeto por el sujeto y referida a ambos ${ }^{19}$. Fichte no lo acepta como principio de la filosofía porque esa proposición enuncia un hecho de conciencia, y todo hecho es justamente aquello que tiene que ser explicado y no puede servir como principio de explicación, sino que se le ha de buscar la razón de por qué existe y de por qué es así y no de otra manera. En concreto tendríamos que deducir desde el Yo real-ideal esas acciones de «distinguir» y de «referir» de las que habla el principio de conciencia, es decir, habríamos de mostrar sus condiciones transcendentales de posibilidad. En realidad ese hecho de conciencia queda deducido en el $§ 17$ la WLnm: la facultad de representación (Vorstellungsvermögen) de Reinhold es el fenómeno de la aparición del Yo en la conciencia natural ${ }^{20}$. El principio para Fichte no puede ser un hecho o Tatsache, "pues el fundamento se halla necesariamente fuera de lo fundado» ${ }^{21}$, sino que es una acción real-ideal originaria del Yo o Tathand-

${ }^{17}$ Carta a H. Stephani, diciembre de 1793 (GA III/2, 28). Esta idea se encuentra repetidas veces en otras cartas de la época.

${ }^{18} \mathrm{GA} \mathrm{I} / 4,231$.

19 Beyträge zur Berichtigung bisheriger Mi verständnisse der Philosophen (Contribuciones a la rectificación de los malentendidos, habidos hasta abora, de los filósofos), Primer tomo, Jena, 1790, p. 167. En Kant esa diferenciación y esa relación se daría en virtud de las categorías de modalidad "posibilidad" y "existencia".

${ }^{20}$ GA IV/3, 491.

${ }^{21} \mathrm{EE}, \mathrm{GA}$ I/4, 206; véase también 187, 190, 211. WLnm-K, GA IV/3, 332. 
lung. Por consiguiente el primer principio no puede consistir en una proposición teórica que se tuviera por evidente, o sea, en un hecho de conciencia que se quisiera situar más allá de toda crítica, pues de toda afirmación cabe pedir su razón o fundamento; incluso de los principios lógicos de identidad y de no contradicción, pues de hecho éstos se basan en acciones transcendentales ${ }^{22}$.

Además Reinhold con su principio de conciencia colocaba el primer principio de la filosofía en el ámbito de lo teórico, no teniendo en cuenta la primacía que tiene lo práctico en la filosofía transcendental. Kant había declarado al inicio del Prólogo a su Crítica de la razón práctica que «el concepto de libertad, en cuanto su realidad es demostrada mediante una ley apodíctica de la razón práctica, constituye la piedra angular de toda la construcción de un sistema de la razón pura, incluso de la especulativa ${ }^{23}$. Siguiendo esta inspiración, Fichte situará su primer principio en esa libertad, y en concreto en la acción real-ideal originaria del Yo, desde la cual se puede deducir tanto lo teórico como lo práctico. Ella sirve además para explicar el sentimiento, tema asimismo de la tercera Crítica kantiana, es decir, funciona como principio de las tres facultades kantianas: conocer, querer y sentir. Esto no ha sido realizado por Kant, el cual se apoya propiamente en un principio arquitectónico, que coloca y distribuye las diferentes partes del sistema, pero con él no las deduce genéticamente según una serie de actos. La posición de Fichte queda bien definida en una carta que le escribe a Reinhold el 28-4-1795:

«A mi entender, la desavenencia consiste en esto: si Usted [Reinhold] ha establecido el fundamento de la filosofía entera, tiene que derivar el sentimiento y la facultad de desear como un modo de la facultad de conocer. Kant no quiere en absoluto subordinar esas tres facultades en el hombre bajo un principio superior, sino que quedan meramente coordinadas. Estoy total-

${ }^{22}$ Recuérdese cómo, en el $\$ 1$ de la GWL, se fundamenta el principio de identidad $(\mathrm{A}=\mathrm{A})$ en la autoposición del Yo o Tathandlung "Yo soy Yo" o "Yo soy"; aquél sirve de camino para llegar a éste, porque éste es lo que lo funda en su forma y validez. Ya Kant había partido de la tabla lógica de los juicios como ratio cognoscendi para obtener su tabla de las categorías o acciones básicas de la objetividad, que serían la ratio essendi de aquéllos, y en una nota había afirmado: "La unidad sintética de la Apercepción es, por tanto, el concepto más elevado del que ha de depender todo uso del entendimiento, incluida la lógica entera y, en conformidad con ella, la filosofía transcendental" (Kant, KrVB 134 nota).

23 AA V, 3-4. 
mente de acuerdo con Usted en que ellas deben estar subordinadas a un principio superior, pero en desacuerdo sobre que ese principio pueda ser el de la facultad teórica [...]. Yo las subordino al principio de la subjetividad en general. Este camino lo cierra Usted enteramente mediante su «Filosofía de los Elementos» al tener ya un principio supremo que yo considero sólo como subordinado; Kant lo deja abierto, pues él únicamente se ha pronunciado contra la subordinación bajo el principio teórico [...]. Yo no he tenido que hacer otra cosa más que unir el descubrimiento de Kant, que señala claramente hacia la subjetividad, y el suyo [... el de] que toda investigación ha de partir de un principio fundamental ${ }^{24}$.

Por esa misma razón no le parece acertada a Fichte la posición que últimamente había adoptado el seguidor e intérprete de Kant Sigmund Beck en su libro Único punto de vista posible desde el cual se ha de enjuiciar la filosofía critica (Einzig möglicher Standpunkt, aus welchem die kritische Philosophie beurteilt werden $m u$, Riga, 1796), pues también Beck opinaba que la filosofía debía fundarse en algo encontrado, en un hecho (Tatsache) teórico, aunque sí aceptaba que ese primer principio debía ser un postulado, como lo hará Fichte.

\section{La intuición intelectual}

El primer principio de Fichte es la intuición intelectual, en virtud de la cual el Yo se pone a sí mismo. Ella es el primer paso, la primera acción del Yo, la que da comienzo a todo lo demás, aunque, como veremos, esa intuición del Yo no se daría sin el concepto del Yo, en realidad tampoco sin todas las otras acciones que se deducirán de ella como haciéndola posible, en un recíproco apoyo propiamente sintético.

«Intuición» hace relación directa con la aprehensión de la realidad, y se contrapone a "concepto», cuya referencia a lo real está mediatizada por la intuición, pues sin ella quedaría vacío de contenido, como una mera palabra. «Intelectual», en oposición a «sensible», quiere decir que esa relación directa con la realidad no es pasiva sino activa, creadora, a diferencia de lo sensible, que incluye ya cierta

${ }^{24}$ GA III/2, 314-315. 
pasividad. O sea, adjetivando a esa intuición de intelectual lo que se quiere decir es que esa realidad e idealidad del Yo no es producida por otra cosa, sino que el Yo es una realidad-idealidad originaria que se constituye como ser y saber en ese acto que Fichte llama «intuición intelectual». En esto él está reelaborando la libertad kantiana: «En la exposición actual [la WLnm] nosotros partimos del objeto inmediato de la conciencia, de la libertad [de la intuición intelectual, § 1], y establecemos las condiciones de la misma. La acción libre es lo más esencial de nuestra investigación» ". Kant había pensado también la libertad como una acción espontánea, es decir, no producida por otra, al contrario de lo que ocurre con los fenómenos, a los que hay que buscarles una causa para hacerlos inteligibles. La libertad es una "realidad en síı, que parte de sí y no es efecto de otra cosa, sino que es un comienzo absoluto (absuelto de toda otra causación) y originario de la acción y de una serie de modificaciones en los fenómenos; por eso la persona es responsable de sí, sujeto de imputación (Zurechnungsfähigkeit). Si esa acción fuera producida por otra cosa, entonces esa otra realidad sería la responsable de mis actos, no yo; pero la conciencia moral nos muestra lo contrario, y nos sirve de camino o ratio cognoscendi para afirmar la libertad. El Yo en Fichte es igualmente esa realidad originaria, pero mientras que en Kant el Yo libre sólo sabía de sí a través del concepto, y en concreto de la ley moral racional (el imperativo categórico), en Fichte el Yo sabe de sí previamente en una intuición intelectual (no habría concepto sin intuición) que le constituye como Yo al ser un acto de unidad indisoluble, inmediata y originaria, de ser y saber, de objeto y de sujeto. O hay una unidad originaria de ser y saber, o siempre permanecerán separados, ciego el uno y vacío el otro, si es que eso pudiera darse:

«El Yo es pensado a través de que ser y pensar son pensados o unificados en cuanto absolutamente idénticos (idealidad y realidad son uno). Esto no significa que un ser y un pensar del Yo son pensados como uno, sino que a través de esta unificación del ser y del pensar el Yo mismo se constituye. Pues el Yo, en efecto, no está aún presupuesto, sino que queremos primero obser-

${ }^{25}$ WLnm-K, GA IV/3, 380.

${ }^{26}$ El imperativo categórico sería para Fichte ciertamente la conciencia racional que la libertad tiene de sí, pero si no la ligamos a una intuición previa de la acción realideal del Yo originario, aparecerá como mero factum de la razón, según lo denomina Kant, y por tanto como una especie de qualitas oculta (véase SSL $§ 3$, Akal, Madrid, 2005). 
var y prestar atención a su surgimiento. Esta conciencia toda y el Yo son completamente lo mismo, sólo que mirados desde dos lados: en la conciencia común es $Y o$, en la filosofía transcendental, identidad del ser y del pensar» .

Es importante señalar que aquí, en este contexto, el término de «objeto» utilizado por Fichte, cuando dice que en la intuición intelectual el Yo es a la vez objeto y sujeto, no significa que el Yo en esa intuición sea o aparezca como un objeto más del mundo, en modo alguno, sino que lo que se quiere indicar es que ahí el Yo también es real, se hace real, mientras que el término de "sujeto" quiere señalar que en esa acción él sabe de sí, es para sí, que es también acción ideal. El Yo es real porque sabe de sí y, por ser un Yo, sólo sabiendo de sí es real como Yo; y a la inversa, sabe de sí porque es una acción real que postula o pide a sí misma su plena realización como Yo. Por tanto, el término de «objeto» tiene dos significados según se aplique a la realidad originaria del Yo o a la realidad conocida del No-Yo, la de los objetos del mundo, ámbito en el que también llegará el Yo a aparecer como un objeto más del mundo, y en concreto como un cuerpo orgánico y articulado. Hay que atender a esa diferencia cuando Fichte nos dice que la intuición intelectual no es un hecho (Tatsache), sino una acción originaria del Yo, creando, para señalarlo, un término nuevo alemán: Tathandlung; se trata «de una actividad pura, que no presupone un objeto, sino que lo produce ella misma, y donde por tanto el actuar (Handeln) se convierte en hecho (Tat)» ${ }^{28}$, en algo real. En consecuencia hay que distinguir entre la realidad-cosa (Tat-Sache), propia de los objetos del mundo, y la realidad-acción (Tat-Handlung) propia y originaria del Yo. No aquí, al inicio de la WLnm, pero sí a la altura del § 6, Fichte nos advierte de ese doble significado del término «objetivo", situándolo, claro está, en ese contexto más avanzado del proceso de deducción:

«... lo subjetivo - lo que se pone a sí mismo-, lo objetivo - la actividad práctica-, y lo que es propiamente objetivo, el NoYo. Lo objetivo tiene dos significados: 1) por oposición a la actividad ideal, es la actividad práctica; 2) por oposición al Yo entero, es el NoYo»"

27 WLnm-K, GA IV/3, 481. "En esa unificación inmediata [sin mediación] de ser y de ver consiste la naturaleza de la inteligencia" (EE, GA I/4, 196).

${ }^{28} \mathrm{ZE} \S 5$, GA I/4, 221.

${ }^{29}$ GA IV/3, 373. 
Por consiguiente, la «intuición intelectual» en Fichte no hace relación, como en Kant, a una actividad capaz de crear el mundo y sus objetos ex nihilo, como sería la acción de un Dios creador y omnipotente, pues no es una acción-saber que vaya hacia los objetos del mundo, sino una que se dirige a sí misma y comprende la acción como acción, como originaria.

«La intuición intelectual en el sentido kantiano es [también] para la Doctrina de la Ciencia un absurdo, que se nos escapa entre las manos cuando queremos pensarla y que no merece nombre alguno. La intuición intelectual de la que habla la Doctrina de la Ciencia no se dirige a ningún ser, sino a un actuar, y en Kant no está designada (excepto, si se quiere, mediante la expresión apercepción pura)».

El primer principio de Fichte es pues una acción real-ideal, una «agilidad» ${ }^{31}$ que sabe de sí y se muestra a sí misma su realidad. El Yo no es primeramente algo, una res o substrato fijo o substancia o alma, que después actuara con libertad, sino una acción real-ideal, y sólo después sobre esa base, en un segundo momento o acción transcendental, aparecerá el Yo como facultad, aunque la conciencia cotidiana lo haya de ver necesariamente a la inversa, según se explicará más abajo.

Por tanto este principio o primera acción del Yo no hay que pensarlo como un acto cerrado en sí mismo y monadológico, aunque contenga en sí también la

${ }^{30} \mathrm{ZE} \S 6, \mathrm{GA} \mathrm{I} / 4,225$. También al tratar de la conciencia moral debería haberla considerado, sigue diciendo ahí Fichte.

${ }^{31}$ VND III, GA I/4, 279. Ortega y Gasset alaba a Fichte por haber comprendido que "el ser es pura agilidad" (Introducción a "Historia de la Filosofía" de Emile Bréhier", en Obras Completas, Revista de Occidente, Madrid, 19737, tomo 6, p. 416). "Sólo Fichte representa un caso aparte. Se advierte que palpa el verdadero ser de la vida" (Historia como sistema, en Obras Completas, t. VI, p. 31 nota). "Empleo el término de "Ser-ágil" en homenaje al genio enorme de Fichte, el primer pensador que define al hombre como siendo primaria y fundamentalmente reine Agilität [pura agilidad]. Sería, de todo el pasado, el filósofo más actual si no le estorbase su patetismo constante, ingenuo y predicante. En Fichte llega a madurez la grande idea de Leibniz, por tanto, la gran idea alemana de que la realidad, la sustancia no es forma, como creían los griegos [...], sino que es vis activa" (Ortega y Gasset, Meditación de Europa, "La dualidad del hombre griego", en Obras completas, t. 9, pp. 278-279 nota; véase también t. 9, pp. 302-303). 
posibilidad de intimidad y de soledad, de estar consigo. Como ya se ha dicho, este primer acto no sería posible sin los siguientes, que son justamente deducidos como necesarios en esa medida. En concreto Fichte señala expresamente en su Segunda Introducción que la intuición intelectual no puede constituir por sí sola un acto completo de la conciencia, sino que siempre ha de aparecer ligada a una intuición sensible ${ }^{32}$, o sea, a la conciencia objetiva del mundo, dado que sin contraposición y distinción no hay conciencia; el acto de identificación del Yo consigo mismo requiere una contraposición con lo otro, de modo que el Yo es una acción sintética, una identidad inmediata y a la vez mediada de múltiples maneras. La intuición intelectual es en verdad el momento inmediato de un sersaber de sí que conllevará asimismo y necesariamente múltiples mediaciones a través de lo otro de sí. No se daría la mediación sin lo inmediato y a la inversa. Lo inmediato sin más, aisladamente, se perdería en su objeto o realidad y no sabría de sí, pues saber de sí requiere saber de lo otro y distinguirse de ello. Lo mediatizado solo, por su parte, nos lanzaría al infinito en dispersión y fuga, disolviéndonos, mientras que ese proceso es constantemente retenido y unificado y constituido como saber gracias al saber inmediato de sí. El primer paso es el de la inmediatez ser-saber, pues ella nunca podrá ser puesta por la simple mediación, que carece en sí de límites; esa inmediatez es, en consecuencia, el inicio o fundamento último de todo otro saber, lo que unifica todo lo múltiple y diverso, y ninguna razón puede ir más allá sin destruirla, sin hacer con ello dependiente al Yo, sin aniquilar por tanto su libertad, lo cual no me está permitido hacer pues iría contra el deber y la razón práctica ${ }^{33}$. Toda mediación, por su parte, se ha de anudar a ese primer momento para sostener y mediar la contradicción en la que se ve envuelto en su mismo objetivo: el Yo quiere saber de sí, pero para ello ha de distinguirse de lo otro, salir de ese primer acto, mas al distinguirse, descubre que no es toda su propia realidad y se ha de imponer a sí mismo la tarea infinita de al menos ir elaborando esa otra realidad enajenada según sus exigencias (racionales).

${ }^{32} \mathrm{GA} \mathrm{I} / 4,217$.

33 WLnm-K, GA IV/3, 347. ZE, GA I/4, 219-220. Véase sobre este punto el artículo de Fichte, "Sobre el fundamento de nuestra fe en un gobierno divino del mundo", traducido en el libro La polémica del ateísmo. Fichte y su época (Dykinson, Madrid, 2009), en especial las páginas 140ss. Ya Kant había señalado esa capacidad ilimitada que la razón teórica tiene de preguntar por el fundamento de todo (KrVA 613-618, B 641646), pero limita su alcance objetivo-real, le niega la capacidad de llegar al fundamento último real y la subordina a la razón práctica o libertad. 
El filósofo ha de ir más allá del horizonte de la conciencia común y alzarse por un acto de libertad, «mediante abstracción y reflexión» ${ }^{34}$, hasta este primer principio, pero no sólo mediante la reflexión conceptual, sino también y sobre todo por medio de su propia intuición interna, a fin de captar que la intuición intelectual es así y que es real. «Lo que sea un actuar, eso sólo se deja intuir, no exponer ni comunicar por conceptos ${ }^{35}$. Por eso Fichte invita a sus oyentes y lectores que piensen primero en algo, por ejemplo en la pared, y después se fijen en ese acto de pensar y lo aprehendan como acción propia. «Aquí el ojo ve el ver del ojo ${ }^{36}$. La corrección de esta intuición del filósofo reside en que el Yo actúa siempre de la misma manera, según su naturaleza y sus leyes, tanto en la intuición intelectual originaria del Yo como en la reproducida por el filósofo, pues el Yo no es más que esa acción de retorno sobre sí (de identificación entre ser y pensar, entre realidad y sujeto), no una res que estuviera detrás de esa acción, de manera que mediante esa acción no surge otra cosa que un $\mathrm{Yo}^{37}$.

«Ese intuirse a sí mismo que se presume en el filósofo y que se da en la realización del acto gracias al cual le surge el Yo, lo llamo intuición intelectual. Ella es la conciencia inmediata de que actúo y de qué hago [por ejemplo, de que muevo la mano, o el pie]; es aquello gracias a lo cual sé algo porque lo hago. Que exista tal facultad de intuición intelectual, eso no se deja demostrar por medio de conceptos, ni qué sea se deja exponer por medio de conceptos. Cada uno ha de encontrarlo inmediatamente en sí mismo, o nunca llegará a conocerla. Pedir que se demuestre mediante razonamientos es mucho más sorprendente de lo que sería la petición de un ciego de nacimiento de que se ha de explicar lo que son los colores sin necesidad de ver ${ }^{38}$.

Kant tendría que haber hablado de ella con relación a la apercepción transcendental, y sobre todo con motivo de la ley moral, «en la que se le pide al Yo un actuar absoluto, sólo fundado en él y en ninguna otra cosa y por consiguiente el Yo es caracterizado como algo absolutamente activo. En la conciencia de

${ }^{34}$ WLnm-K, GA IV/3, 439. Hay que abstraer de todo objeto y reflexionar sobre el acto del sujeto, volcar toda nuestra atención en él.

35 ZE, GA I/4, 215.

36 WLnm-K, GA IV/3, 354.

37 ZE, GA I/4, 214-216, 218. WLnm-K, GA IV/3, 338-339.

38 ZE, GA I/4, 216-217. 
esta ley, la cual sin lugar a dudas no es una conciencia sacada de otra cosa, sino inmediata, se funda la intuición de la actividad propia y de la libertad $\iota^{39}$.

\section{El concepto del Yo}

En ese primer paso o momento, el de la intuición intelectual, que servirá de base a todo ser y saber del Yo, éste no logra sin embargo propiamente saber de sí, y por tanto tampoco ser un Yo, ponerse y realizarse como un Yo. Él en verdad se pierde en ese acto primero, como ocurre en toda intuición como tal. De ella Kant ya había dicho que es en cuanto tal, aisladamente, blind, ciega: «intuiciones sin conceptos son ciegas ${ }^{40}$. Eso mismo ocurre con este primer acto en Fichte: «la conciencia inmediata no es conciencia en absoluto, es un oscuro (dumpfes [indistinto, sordo]) ponerse a sí mismo del que no sale nada, una intuición que no intuiría nada ${ }^{41}$. Por eso como tal no "aparece en la conciencia» cotidiana, pues «nunca es algo objetivo, sino siempre lo subjetivo" ${ }^{42}$, "es en toda conciencia lo que está siendo consciente, pero no aquello de lo que uno es consciente ${ }^{43}$ ». Ella no es una conciencia completa, sino sólo un elemento de la misma. El Yo se pone en la intuición intelectual, pero eso lo ve plenamente sólo el filósofo, de manera que el Yo tendrá que llevar a cabo una segunda acción para darse cuenta de la primera como acción suya.

El Yo se pierde en ese acto primero porque se identifica plenamente con él y carece de perspectiva para verlo como tal; no es capaz de contraponerlo a otra

${ }^{39}$ ZE, GA I/4, 219; véase también 224 ss.

${ }^{40}$ Kant, $K r V$ A 51, B 75.

41 WLnm-K, GA IV/3, 361.

42 O.c., 353. «En consecuencia no es tampoco una conciencia, ni siquiera una autoconciencia; y únicamente por eso, porque mediante ese mero acto no llega a formarse ninguna conciencia, se deduce otro acto gracias al cual surge para nosotros un NoYo; únicamente así hay un progreso en el razonamiento filosófico y es posible la exigida deducción del sistema de la experiencia. Mediante el acto descrito, el Yo es colocado meramente en la posibilidad de la autoconciencia y, con él, de toda otra conciencia; pero no surge aún ninguna conciencia real. El acto indicado es meramente una parte (y una que sólo puede ser separada por el filósofo, pero que no lo está originariamente) de toda la acción de la inteligencia, gracias a la cual ésta produce su conciencia” (ZE, GA I/4, 214).

43 WLnm-K, GA IV/3, 354. 
cosa, no hay posibilidad de distinguirlo, siendo así que yo sé de algo cuando lo determino como algo distinto de las otras cosas. Sólo pensando algo contrapuesto a ella determino mi intuición, y eso es comprenderla por medio del concepto ${ }^{44}$. Nada se piensa ni se sabe propiamente y de manera determinada si no es contraponiéndolo a lo otro ${ }^{45}$. Esta ley de la contraposición, que rige en el pensar y el saber, juega un papel tan esencial en la articulación de la WLnm que casi podríamos proponerla como su segundo principio. En efecto, de ella se dice aquí: «todo el mecanismo del espíritu (Geist) humano reposa sobre la necesidad del oponer ${ }^{46}$ o contraponer algo a otras cosas y captarlo conceptualmente como siendo esto y no lo demás ${ }^{47}$. Al igual que ocurría en la GWL (Grundlage), donde el segundo acto de ponerse el Yo, para saber de sí como Yo, era el origen de su salir de sí y descubrir el mundo ${ }^{48}$, también aquí, en la WLnm, «este acto de oponer» o contraponer, con el propósito de saber de sí determinadamente y captarse como Yo, "es el fundamento de toda salida fuera del Yo», primero de la salida de la intuición intelectual hacia el concepto del Yo, y después de la salida del Yo hacia el No-Yo o mundo ${ }^{49}$. A partir de esa necesidad de oponer y de mediar entre los opuestos, o sea, por la necesidad de identidad y diferencia (unidad sintética), irán surgiendo los distintos actos y momentos del sistema e irán siendo deducidos en cuanto necesarios para el mismo.

Esa contraposición, imprescindible para el saber, es lo que le falta al primer acto, a la intuición intelectual. Si el Yo se quedara allí, sería una actividad realideal sin oposición a nada, o sea, sin límite, y prácticamente sin conciencia. La identidad ser-saber anularía toda diferencia y con ello todo saber. Por eso el Yo

${ }^{44} \mathrm{ZE}, \mathrm{GA} \mathrm{I} / 4,249 .+$

${ }^{4}$ WLnm-K, GA IV/3, 348, 352, 359. WLnm-H, GA IV/2, 34, 41. VLM, GA IV/1, 329, 340. Fichte llama a esta ley "la ley de la reflexión" (WLnm-K, GA IV/3, 459) o "ley de la reflexión de los opuestos" (o. c., 352) o "principio de la determinabilidad" (o. c., 363). «El principio de la determinación por oposición es éste: Nada es pensado de manera determinada, a no ser que se le oponga algo" (VLM, GA IV/1, 334-335). "toda determinación, cualquiera que sea la cosa que se determine, sucede mediante contraposición" (VND, GA I/4, 279).

46 WLnm-K, GA IV/3, 356.

${ }^{47}$ Es algo similar a lo que señala Heidegger cuando dice que el "como" (als) es la estructura básica de la comprensión (die Als-Struktur des Verstehens), y por eso toda comprensión es interpretación, un comprender algo como algo (Ser y tiempo § 32)

${ }^{48}$ GWL $\$$ 5, GA I/2, 408-409.

49 WLnm-K, GA IV/3, 352. 
no puede permanecer ahí encerrado, y se ve obligado a salir de esa conciencia inmediata, reflexionar sobre sí, ponerse por segunda vez: esa acción es lo que Fichte denomina el concepto del Yo. El Yo, para comprenderse como Yo, como lo activo, como acción, ha de retornar sobre sí y contraponerse al reposo (Ruhe). «Reposo» es el nuevo elemento que aquí aparece y que se añade sintéticamente al primero, comprendido ahora sí como actividad; esa actividad y ese reposo irán siendo sucesivamente determinados más concretamente. Por tanto, esta segunda acción del Yo reflexiona sobre la primera, sobre la intuición intelectual, la fija, y se comporta con ella como el concepto con la intuición. Es entonces cuando la primera acción aparece como intuición, en contraposición con la segunda, que funciona por tanto en relación a aquella como concepto; no hay propiamente intuición sin concepto, ni puede haber en modo alguno concepto sin intuición, y aquí en concreto ningún concepto originario del Yo sin intuición originaria del Yo; de ahí que a la base de la conciencia moral, como concepto racional del Yo, Fichte ponga una intuición intelectual, que Kant no habría sabido ver ${ }^{50}$.

El Yo es capaz de salir de la intuición intelectual, de no quedarse atrapado en ella, en virtud de la ilimitada potencia y creatividad de su actividad ideal que, justamente por su idealidad, no está atada irremisiblemente a ningún límite, y es capaz por ello de guiar asimismo la actividad real del Yo a la elaboración real, racional y progresiva de cualquier límite por medio del concepto de fin, como iremos viendo. Pero ese salir de la intuición no significa que esta primera acción del Yo deje de ser, sea abandonada y desaparezca, pues entonces la segunda no sería posible: ambas se encadenan y forman una unidad sintética, una unidad en la diferencia, pues el concepto no es externo a la intuición, sino que la segunda acción tiene en cuenta la primera, se apoya en ella, la convierte en su objeto propio. Por consiguiente el concepto incluye en sí la intuición, y sin ella quedaría vacío, o mejor dicho, no tendría lugar. En caso contrario serían dos actos yuxta-

50 "A esa actividad interior captada en su reposo se le llama generalmente concepto. Era por tanto el concepto de Yo el que estaba unido con la intuición del mismo necesariamente, y sin el cual hubiera sido imposible la conciencia del Yo; pues sólo por el concepto queda completada y abarcada la conciencia. El concepto nunca es otra cosa que la actividad misma del intuir, sólo que no captada como agilidad sino como reposo y posibilidad de determinación; eso mismo ocurre también con el concepto de Yo. La actividad que retorna a sí, comprendida como fija y constante, gracias a lo cual coinciden por tanto ambos, el Yo como algo activo y el Yo como objeto de mi actividad, es el concepto de Yo" (VND, GA I/4, 280). 
puestos e indiferentes, de modo que el Yo estaría dividido, no podría reconocerse a sí mismo y se disolvería como Yo; no habría ni intuición ni concepto.

En consecuencia, esos dos momentos o acciones, la intuición del Yo y el concepto del Yo, son considerados por Fichte como formando un solo acto, y ambos son tratados en el $§ 1$ de esta exposición de la DC: no habría intuición sin concepto ni concepto sin intuición. En realidad tampoco habría intuición ni concepto del Yo sin todos los otros actos que configuran todo el sistema de la DC, pero estos dos primeros forman como la almendra, el núcleo germinal, mientras que todos los demás en realidad sirven para aclararlo, para mediar en la dualidad actividad-reposo que le acaba de surgir al Yo. Cuando Fichte habla del primer acto del Yo generalmente los incluye a los dos. También hay no obstante diferencia entre ambos: la intuición sólo puede ser captada por la intuición, y de ahí que Fichte les requiera a los oyentes y a los lectores que presten atención a sus propios actos, a la intuición inmediata y directa de sus acciones ${ }^{51}$, a fin de que sepan de qué realidad está hablando su filosofía, y no quede ésta en ser meras palabras sin contenido real, una filosofía de meras fórmulas ${ }^{52}$. Y lo mismo le sucede al concepto o pensar, que únicamente puede ser captado y comprendido por el pensar, y no por el mero intuir. Pero también hay identidad sintética, pues el Yo es el mismo, la actividad ideal la misma en ambos, aunque en momentos diferentes, y por tanto se trata de un acto sintético de autoidentificación (el Yo no es una identidad sino un acto de autoidentificación, y ese acto es el fundamento transcendental del principio lógico de identidad, que es formal y analítico); de ese modo la segunda acción se engarza y

${ }^{51}$ Así sucede, por ejemplo, en este $\$ 1$ de la $W \operatorname{Lnm}(\mathrm{GA} I V / 3,345)$ y al inicio de la Primera Introducción: "Presta atención a ti mismo: aparta tu mirada de cuanto te rodea y dirígela a tu interior; esta es la primera petición que hace la filosofía a su aprendiz. De lo que se habla aquí no es de nada que esté fuera de ti, sino solamente de ti mismo" (EE, GA I/4, 186).

52 "Formular-Philosophie, sería la clase de filosofía que no quiere hacer Fichte, véase por ejemplo GWL, GA I/2, 220; Sittenlehre, GA I/5, 178; o el punto I de la Introducción a la GNR (GA I/3, 313-318), que se titula justamente así: "Cómo una ciencia filosófica real se diferencia de una mera filosofía de fórmulas".

${ }^{53} \mathrm{El}$ primer acto, el de la intuición intelectual, es ya presentado por Fichte como un retornar sobre sí mismo (ein Zurückgehen in sich selbst) (ZE, GA I/4, 214; ver también 265-266). Eso presupone, claro está, la existencia de un límite del Yo, de su realidad, límite que después será deducido a partir de esa autoposición del Yo y su necesidad de saber de sí, pues él lo ha de elaborar desde sí a fin de que sea para él. Todos los 
se identifica con la primera, sobre la que retorna para captarla, pues el Yo quiere saber de si $^{53}$.

La intuición intelectual es la primera posición del Yo: el Yo se pone. Pero el Yo ha de ponerse por segunda vez a fin de que él sea para sí y sepa de sí como actividad originaria. En este segundo acto el Yo se pone como (als) Yo, y por esa necesidad de volverse a poner contraponiéndose como un Yo frente a lo que no es Yo, habrá de tomar conciencia de lo otro y le surgirá el mundo; es decir, ese "como» implicará en realidad una serie de actos subsiguientes, sólo iniciados en esta segunda acción del Yo. En la primera exposición pública de la DC, en el § 1 de la $G W L$, Fichte había seguido el orden ascendente de la reflexión y condujo al oyente (y al lector) desde el principio de identidad $(\mathrm{A}=\mathrm{A})$, como hecho evidente de la conciencia, al concepto del Yo: «Yo soy Yo» (su fundamento transcendental), y de ahí a la intuición "Yo soy» (A es). En la WLnm se procede en

momentos son a la vez, lo primero es la síntesis como había dicho Kant, y sin el límite no se daría ese retorno del Yo, pero el límite se ha de deducir en parte desde Yo en el sentido de que idealiter es para el Yo sólo gracias a esa vuelta en la que se intuye como realidad-idealidad. Después, en el concepto del Yo, aparecerá un reposo y actividades no puestas, y ése será el primer movimiento para reconocerse como limitado y saber de lo otro. A ese concepto del Yo lo conceptúa Fichte también como un retornar sobre sí (VND, GA I/4, 272). Luego el Yo es una actividad, y específicamente la actividad de retornar sobre sí mismo, tanto en su intuición como en su concepto. Eso es lo que Fichte quiere que hagan sus oyentes y lectores, que salgan de su natural atención a los objetos externos y retornen hacia su propio acto de pensar. No obstante, ésa, la del retorno, es una descripción desde la reflexión y no propiamente desde la génesis, por eso Schelling y Hegel califican la filosofía de Fichte como una filosofía de la reflexión. En el punto de vista propiamente genético, el Yo debería ser entendido como un acto meramente tético (Fichte usa ese término), es decir, como un estar originaria e inmediatamente en sí (intuición intelectual) desde el inicio y no como un retorno, pues si sólo pudiera intuirse en el retornar, aquello hacia lo que se retorna no sería ya ello mismo un intuir, sino una especie de cosa en sí previa, con el cual la actividad yoica que retorna (ya sea intuición o concepto) no podría en modo alguno identificarse. Deberíamos pensar que esa acción real-ideal o intuición intelectual primera es hacia la que retorna la acción ideal de la reflexión o concepto del Yo, de modo que el Yo se identifica con ella y la comprende como su acción-ser. Claro que sólo entonces la intuición se convierte en intuición, y por tanto el retorno y con ello el límite le son en esa medida constitutivos. Esto elimina la tentación de pensar el Yo de Fichte como algo substante y transcendente, pues en realidad es el presupuesto necesario para explicar nuestra experiencia como la síntesis dinámica que es.

54 Bien entendido que "ascendente» y "descendente» no son sino metáforas. 
sentido contrario, en el orden descendente ${ }^{54}$ de la génesis, y se va de la intuición al concepto, o sea, del «soy» como posición primera, real-ideal, en la intuición intelectual, al «Yo soy (como) Yo» en cuanto posición segunda en virtud del concepto del Yo. En el «Yo soy (como) Yo» (el surgido en la conciencia gracias a la reflexión transcendental, no simplemente en virtud de la reflexión cotidiana o común), el primer «Yo» corresponde a la primera acción del Yo o primera posición absoluta de sí que tiene lugar en la intuición intelectual en cuanto sujetoobjeto (saber-ser, idealidad-realidad), mientras que el segundo "Yo» es la segunda posición o acción del Yo, que a la vez se identifica con la primera acción (eso es la cópula), y que es la acción que Fichte denomina aquí concepto del Yo, donde de nuevo aparece el Yo como sujeto(desdoblado)-objeto.

Si la primera acción de autoposición o Tathandlung muestra la libertad, espontaneidad y originariedad reales del Yo, esta segunda acción de retorno sobre sí muestra su esencial reflexibilidad, su carácter de autoconciencia y de ser «para sí». En virtud de esa autorreferencia esencial, el Yo puede saber de sí y de todas sus acciones y determinaciones, y gracias a ello conocer también el mundo; es decir, la autorreferencia no enclaustra al Yo como si fuera una opacidad, sino que lo abre, pues constituye una transparencia o luz ${ }^{55}$. Por esa autorreferencia constitutiva, el Yo puede utilizar los adjetivos posesivos y pronombres posesivos y personales; pero si tenemos en cuenta que ese Yo transcendental es tan individual como comunitario, entonces no sólo podría usar la primera persona: mi o mío, sino también las cinco restantes. Cuando en el texto aparece «mi»o «Yo» sabremos ya que no se trata del Yo empírico, individual, y podremos también usar asimismo las otras personas, pues todas ellas son formas de la autorreferencia: «Ningún Tú [si no hay] ningún Yo; ningún Yo, ningún Tú »56.

\section{Lo determinable: la facultad y el NoYo}

Dejemos atrás el $§ 1$ de la $W L n m$ y pasemos al $§ 2$. El Yo ha descubierto que es a la vez actividad y reposo: "ninguna actividad sin $s u$ reposo» ${ }^{57}$ es la conclu-

${ }^{55}$ Fichte utiliza mucho esa metáfora de la luz por ejemplo en la exposición de su DC de 1805.

56 GWL $\$ 4$, GA I/2, 337.

57 WLnm-K, GA IV/3, 353 
sión. Entonces tiene lugar la tercera acción del Yo (aunque podríamos tomar las dos primeras como una sola, según se dijo, ahora la claridad de la exposición requiere de nuevo el desdoblamiento). En esa tercera acción el Yo reflexiona sobre el nuevo elemento que le ha surgido gracias al concepto: el reposo, y reflexiona sobre él contraponiéndolo a la actividad ya puesta, es decir, vuelve sobre la acción anterior, la del concepto del Yo, para saber de ella. ¿Por qué, si era un concepto? Porque le resulta necesario al Yo para tomar conciencia de ese reposo como tal y saber qué es lo que allí ocurre. El Yo mientras actuaba, aquí en concreto mientras llevaba a cabo su segunda acción, no reflexionaba sobre esa misma acción sino sólo sobre la primera, o mejor dicho (para eliminar el empírico "mientras» que puede estorbar al introducir una temporalidad que aquí no se daría), en la acción misma el Yo no puede reflexionar también sobre ella, sino que ésos son dos actos diferentes. Estamos hablando de los actos transcendentales primeros; una vez constituida la conciencia, podemos muy bien actuar y reflexionar a la vez sobre lo que estamos haciendo, pero también ahí los distinguimos como dos acciones, y es esa distinción la que aquí estamos considerando. El concepto del Yo es también una acción, y reflexionar sobre ella como tal es otra diferente, una siguiente que se enlaza sintéticamente con la anterior. Por eso el Yo se pierde en el mismo concepto del Yo o segunda acción, no logra verla como tal, y se ve obligado a una nueva acción-reflexión; es decir, la acción "concepto del Yo», que era concepto en relación con la acción primera o intuición intelectual, es al mismo tiempo intuición-acción del Yo respecto de sí misma, produciendo de hecho algo: el reposo, y se comporta igualmente como intuición en relación con la acción tercera, que la fija y la determina en su carácter o esencia.

¿Qué carácter o esencia? El reposo (o concepto del Yo) aparece como lo determinable en contraposición con la actividad (intuición del Yo) que es lo determinado en cuanto que es esta acción y no otra. En efecto, el reposo aparece como lo indeterminado, como lo que no está decidido y concretado, la actividad (posible) en reposo del Yo, a partir de lo cual saldría la actividad determinada como un acto de limitación del Yo a una concreta, particular. El Yo comprende entonces su acción como un pasar o transitar (Übergehen) de lo indeterminado-determinable a lo determinado, aquí del reposo a la acción, pues sólo así la acción es entendida como tal, como acción y como una que el Yo mismo emprende. Este esquema del paso o tránsito desde lo determinable a lo determinado (lo finito, lo concreto) se repetirá frecuentemente y regirá buena parte del proceso a lo largo de la WLnm. 
Ahora bien, si esa acción es determinada y comprendida como tal, eso quiere decir que ella se contrapone a otras actividades posibles que no son realizadas. En virtud de esta contraposición, lo indeterminado-determinable, o sea, el reposo (Ruhe) del Yo, adquiere el carácter de «actividades que no son puestas». Pues bien, bajo esta nueva luz, la proyectada por la tercera acción, lo determinable aparece en una doble y contrapuesta faz para el Yo: como facultad del Yo y como No-Yo. Veámoslo.

A/.- En primer lugar como facultad (Vermögen) o capacidad o potencia del Yo. El reposo lo es primeramente de la actividad, y como toda actividad lo es del Yo, el reposo aparece primeramente como reposo del Yo o como su actividad en reposo, o sea, como el abanico de sus posibles actividades, aquellas que no son puestas o realizadas por el Yo, pero que él tendría la facultad o capacidad, el poder o la potencia, de realizarlas, si así lo decidiera. Por tanto ese reposo se ve ahora como algo (aún) indeterminado, pero determinable por el Yo, y esas actividades suyas en reposo constituyen su facultad.

En contraposición a esa posibilidad-facultad, la actividad concreta realizada se capta como la realmente puesta. Más aún, para comprender como suya su acción, la que, según hemos visto, constituyó el primer momento de su génesis, el Yo se ve desde aquí partiendo de su estado de indeterminación, pero determinable por él, hacia su acción, es decir, la ve como surgiendo de un Yo-Vermögen que sería previa y que vendría a ser su substrato o substancia, desde donde él se determinaría a realizar esa actividad en concreto. Por tanto, primero habría un Yo-Vermögen-substancia-reposo, el cual después se pondría a actuar cuando así lo decidiera. Esta inversión del curso real de la génesis es un hecho radical de la conciencia. El filósofo sabe (o al menos eso es lo que propone) que sucede lo contrario, a saber, que lo primero es la acción real-ideal del Yo (intuición intelectual), y que partiendo de esa realidad suya el Yo reflexiona sobre sí, y esta nueva acción o concepto de Yo es la que da lugar al reposo y a la facultad, a la posibilidad, en verdad al concepto de todas sus posibilidades o voluntades a priori, al ámbito de las posibilidades racionales, pues lo determinable «es dado por la naturaleza de la razón ${ }^{58}$. El filósofo advierte que el Yo como facultad no es una res o

58 WLnm-K, GA IV/3, 368. También para Kant el ámbito de la posibilidad lo da la razón, y sobre todo la razón práctica. 
cosa en sí que fuera anterior a la acción real del Yo e independiente de ella, sino que propiamente esa facultad o potencia es como aparece (en parte) la segunda acción (el concepto del Yo) cuando es vista desde la tercera acción, en la que ahora estamos. Son las posibilidades (racionales) del Yo que su realidad solicita, pide, exige, plantea. La facultad del Yo o Vermögen apunta a la razón, cuyas posibilidades o exigencias nunca podrá agotar el Yo-individuo, ni tampoco el Yo-comunidad a lo largo de toda su historia, de modo que, debido a nuestra finitud, siempre estaremos en camino de su realización ${ }^{59}$.

La conciencia común o natural lo ve a la inversa. Según ella, primero sería el Yo como facultad y posibilidad y después, partiendo de él, vendría la acción. Así lo ha de entender en virtud de la ley de la contraposición, al verse y encontrarse a sí misma actuando, y porque la posibilidad (el Yo como facultad) que ella pone como precediendo a la realidad de la acción se apoya ya en un Yo real constituido que le sirve de fundamento existencial; pero aquí estamos hablando de las acciones primeras, transcendentales, constituyentes, las que generan el Yo. Esta inversión representará una de las ilusiones más inquebrantables y tercas de la conciencia común, que primero se piensa como substrato y después como acción, pues ésta es comprendida como paso de lo determinable a lo determinado. Por eso la conciencia natural se comprende a si misma como la acción de una substancia o res, y se cosifica.

Si yo he de percibirme como actuando, entonces he de presuponerme como ya puesto, como algo que ya es y que después pasa a la actividad, como transitando del reposo a la actividad, eso piensa la conciencia común. En ella el YoVermögen es por tanto concebido como previo a la acción con la cual el Yo se identifica, no es captado como acción del Yo mismo (acción que Fichte denomina "concepto del Yo») y en consecuencia el Yo se encuentra a sí mismo como dado a sí mismo, como «arrojado» diría Heidegger, o bien como "creado", y nunca será consciente de su primer momento, como tampoco de su último o muerte. «Lo determinable que se ha de presuponer recibe el carácter de la objetividad, dice Fichte aunque en un momento posterior de la deducción. Aparece como algo encontrado, dado, presente sin nuestra intervención ${ }^{60}$. Ese Yo-facultad, esa

\footnotetext{
59 Véase el final de la primera lección en BG (GA I/3, 31-32).

60 WLnm-K, GA IV/3, 443.
} 
Vermögen, es lo supremo para la conciencia común, pues en ésta no aparece propiamente la intuición intelectual, sino que ella sólo llega al concepto ${ }^{61}$, aquí al concepto del Yo; ella nace en el ámbito de reflexión que abre el concepto, es una conciencia reflexiva. A la conciencia común le parece necesariamente que lo primario es el concepto, la facultad, el reposo, el Yo substante; ella surge gracias a esa inversión, y por eso no capta que lo primario es la acción, sino que parte de yoes en sí y de cosas en sí.

Otra cuestión distinta sería la de preguntarse no ya qué es el Yo antes de actuar, sino ¿̇de dónde puede venir la realidad del Yo, de dónde surge su realidad o primera acción real-ideal, la que da lugar a la intuición intelectual como momento inicial en su larga auto-construcción? ¿de la nada o de una realidad-idealidad? Al preguntar así estamos pensando, al menos en un primer momento, en un yo individual, y los yoes individuales surgen en el tiempo, pues, según Fichte, han de estar precedidos por otros yoes individuales que le invitan o exhortan o requieren (Aufforderung) para que sean desde sí, libres, un tema que se verá en los $\S \S$ 16 y 18. Entonces el yo individual o individuo racional se descubre como siendo una parte de una comunidad de seres racionales libres, lo que Kant denominaba "el reino de fines". Aún así vemos que ninguno crea al otro, ni lo produ$\mathrm{ce}^{62}$, sino que su acción de requerimiento es sólo una conditio sine qua non pero no un fundamento. Si lo fuera, eso anularía la libertad de yo individuo, y éste no sería un Yo. Entonces la realidad originaria de esos yoes individuales ¿̨de dónde vienen? Algunos dirían que de la naturaleza orgánica, pero eso sería un materialismo transcendental que no tiene en cuenta la diferencia entre la naturaleza y el Yo, a no ser que pensemos una naturaleza que no fuera meramente mecánica, heterónoma, sino también acción subjetiva, sujeto-objeto. Otros abogarían por un Dios creador, lo cual destruiría asimismo la libertad, pues la creación es pensada a través de la categoría de causa, y ésta es una categoría de lo fenoménico, de lo heterónomo ${ }^{63}$. ¿Proceden entonces de la nada, como una autocreación ex nihilo? Eso sería un concepto contradictorio, por no decir mágico. Kant sostiene que no se puede ir preguntando así, con esos conceptos, ante la aper-

${ }^{61} \mathrm{VND}, \mathrm{GA} \mathrm{I} / 4,280-281$.

${ }^{62} \mathrm{Ni}$ siquiera biológicamente los padres causan al hijo, sino que unas células de ellos se desprenden y comienza su vida propia desde sí, usando a la madre como habitáculo o nicho temporal. La vida es y se desarrolla desde sí, y si no, no es vida.

${ }^{63}$ Kant, Religión, AA VI, 142. 
cepción transcendental y la libertad, pues ahí esa pregunta carece de respuesta, o mejor dicho, está mal planteada pues nos conduce a lo suprasensible, a lo incontrolable; hemos de poner entonces límites a esa pretensión de la razón teórica y así conseguimos además ponerla en armonía con su pretensión práctica, dado que el total determinismo teórico anularía al sujeto, a su espontaneidad ideal y real, a su libertad, a la moralidad. Ésa es también la posición del primer Fichte ${ }^{64}$. Poco después, en la transición, pensará que esa comunidad de seres libres señala una voluntad pura que determina a los yoes su delimitación ${ }^{65}$. El segundo Fichte irá más allá aunque con otros instrumentos, y propondrá que esos yoes individuales surgen dentro o desde de la manifestación del Ser absoluto, como reflejo de su reflexibilidad, una manifestación que da lugar a toda la realidad que conocemos. Schelling y Hegel afirmarán asimismo que esos yoes individuales son momentos del despliegue de lo Absoluto, un despliegue que se ha de realizar también en momentos de libertad, en seres libres.

B/.- En segundo lugar, el reposo (Ruhe) aparece en esta tercera acción del Yo no sólo como Yo-facultad, sino también, en segundo lugar, como un No-Yo. En efecto, desde el reposo se ve que el Yo se pone y se identifica con una actividad determinada, distinta de otras acciones que no son puestas, es decir, lo determinable contiene actividades posibles del Yo que no se ponen, que no se realizan. Por consiguiente la posición del Yo en una actividad determinada conlleva también necesariamente una no-posición del Yo, de sus otras posibles actividades, y en esa medida una posición de un $N o-Y o$, que ocuparía la realidad no actualizada del Yo, todavía de una manera indeterminada y determinable, como hemos visto que es el reposo. El carácter del No-Yo es ser mero reposo, el no-ponerse desde sí, lo contrapuesto real al Yo, el ser inerte como opuesto a la auto-actividad propia del $\mathrm{Yo}^{66}$.

${ }^{64}$ Véase su artículo "Sobre el fundamento de nuestra fe en un gobierno divino del mundo", publicado en el libro La polémica sobre el ateísmo. Fichte y su época (Dykinson, Madrid, 2009, pp. 137-147).

${ }^{65}$ Fichte, El destino del hombre, Libro tercero, punto IV, GA I/6, 289 ss.

${ }^{66}$ Así tenemos ya el significado de las cuatro letra-signos que aparecen en el texto: A es la actividad del Yo, B es el reposo, C es el reposo del Yo o el Yo como facultad, como actividad en reposo, y D es el No-Yo. 
En relación con el No-Yo, la facultad se encaminará hacia la intuición externa, contrapuesta a la interna o intelectual. Entonces el No-Yo aparecerá como carente de intuición (de acción), como lo intuido. Esto dará lugar a la serie objetiva, mientras que la facultad en relación con los dos primeros pasos, intuición y concepto de Yo (su facultad), dará paso a la serie subjetiva. En consecuencia lo determinable o «esa determinabilidad aparece aquí como la facultad de pensar Yo o No-Yo" ${ }^{67}$. Esta es la duplicidad con la que surge el Yo originario; él es unidad pensar-ser, sujeto-objeto, idealidad-realidad, pero en su mostrarse a sí mismo y por tanto generarse él, se aparecerá a sí mismo (en el fenómeno) primeramente no tanto en la unidad, sino en una inevitable duplicidad de lo subjetivo y lo objetivo ${ }^{68}$, del Yo-facultad y del No-Yo (las dos caras del reposo). Sólo la reflexión transcendental los propone como dos momentos de una misma acción o realidad, una unidad siempre presupuesta por toda conciencia y reflexión, que se halla a sus espaldas, y por eso es para ella lo incomprensible (unbegreiflich) ${ }^{69}$, lo no captable por conceptos, objeto sólo de una intuición, de un saber inmediato que Fichte, siguiendo a Jacobi, gusta de denominar «fe» (Glauben).

${ }^{67}$ WLnm-K, GA IV/3, 357.

${ }^{68}$ WLnm-K, GA IV/3, 505, 509, 514.

${ }^{69}$ O.c., 494, 501. 
